\title{
A Sociedade Civil Falante E o Projeto Político da Modernidade
}

Sergio B. F. Tavolaro

RESUMO: O presente artigo pretende realizar algumas reflexões em torno do "modelo procedimental de democracia" de Jürgen Habermas, analisando os atores sociais que se encontram no cerne de suas possibilidades de implementação: os novos movimentos sociais. Finalmente, pretendemos considerar alguns dos aspectos que delineiam as discussões a respeito da sociedade civil organizada no Brasil a fim de podermos vislumbrar as possibilidades de um projeto político-normativo como esse em meio as especificidades politicas brasileiras.

UNITERMOS: modernidade; teoria democrática; movimentos sociais.

Uma variedade incrível de fenômenos sociais, cada qual com sua dinâmica própria, independente, ocorrendo em simultaneidade para formar a totalidade do mundo moderno. Esse traço caracteriza a "polifonia" da modernidade, fonte inspiradora de inúmeras reflexões que procuraram dar ordem a esse conjunto de fenômenos aparentemente desconexos. As empreitadas teóricas que se colocaram como tarefa a apreensão desse "mundo polifônico" nos despertam sensações semelhantes às de Max Weber ao tomar contato com a obra wagneriana Tristão e Isolda, conforme nos revela Cohn (1979): "Não é difícil imaginar o fascínio de Weber por essa escritura que permite tratar de modo simul- 
tâneo o desenrolar rigorosamente coerente de temas que ocorrem, conforme a lógica de cada qual, por linhas paralelas, para no final formarem um todo construído pela vontade livre mas disciplinada de um pensamento criador: a obra" (p. 3). O sentimento de estupefação, assombro frente ao inesperado, o temor da impossibilidade da apreensão teórica da nova (des)ordem parecem ter frequentado as empreitadas que se colocaram como desafio a análise do conjunto dos fenômenos modernos. Apesar de tudo, resultados positivos foram alcançados e, difícil imaginar, propôs-se até mesmo um modelo normativo para esse complexo mundo que nos salta aos olhos. Procurou-se caminhar de maneira a considerar os aspectos positivos que o processo de individuação trouxe, levando-se em conta, porém, a necessidade de se estabelecer normas intersubjetivamente elaboradas, com referência em "comunidades de comunicação", sem que isso significasse o retrocesso a concepções de mundo provincianas. Também as novas formas de reificação foram consideradas na tentativa de estabelecer relações de nova ordem entre o mundo da vida e os subsistemas que, na modernidade, se autonomizaram e passaram a colonizar âmbitos sociais comunicativamente mediados.

Procuraremos discutir aqui três aspectos absolutamente interconectados: a. a elaboração teórica de um modelo político-normativo democrático, chamado "procedimental", com base nas análises realizadas por Jürgen Habermas, autor que, como se sabe, credita o adjetivo "inacabado" ao projeto da modernidade iniciado com o Iluminismo; $b$. as reflexões em torno da revitalização da sociedade civil organizada que, conforme vem trabalhando a bibliografia, é elemento central para uma normatividade que leve adiante o potencial emancipatório (na medida em que autonomizante) do mundo moderno; c. o debate em torno do fortalecimento da sociedade civil brasileira, e o caráter moderno de suas organizações. É esse o objeto de nossas preocupações no presente artigo, tarefa das mais interessantes na medida em que, como nos lembra 
Habermas (1987), a modernidade encontra-se completamente abandonada a si mesma, tendo que extrair de si mesma sua normatividade.

\section{O MOdelo Procedimental de DEMOCRACIA: O PROJETO POLÍTICO DA MODERNIDADE}

O conceito de modernidade, de acordo com Claus Offe (1987), apresenta um duplo status: de um lado, descreve as características dos processos sociais que resultaram na presente compleição social; de outro, estabelece uma dimensão de avaliação em que idéias ou relações sociais pré ou anti-modernas são criticadas como regressivas em relação a um ponto de vista moderno. Tal dualidade decorre do fato de que as estruturas que se desenvolveram nas sociedades modernas podem ser entendidas como a realização de intenções normativas e projetos revolucionários, gestados no seio de elites modernizantes, cujas origens datam do século XVIII; suas mais marcantes realizações foram a industrialização britânica e a economia política clássica, a Revolução Francesa e a filosofia do Idealismo alemão. A idéia normativa propulsora, segundo o autor, desse processo de modernização europeu foi a emancipaşão da Rąão e a subjetividade.

Desde o século XVIII, o desenrolar desse processo, socialmente e intelectualmente moldado pela Renascença, pela Reforma e pelo Iluminismo, se concretizou em institucionalizações políticas que podem ser caracterizadas esquematicamente pela seqüência: Estado-nação > Estado constitucional > Estado democrático > Estado de bem-estar. Pode-se dizer que a passagem de cada uma dessas instituições para a seguinte significou um avanço na dimensão normativa: parece ser inegável que exista aí uma transformação em direção à expansão da autonomia e de autodeterminação já que os indivíduos foram gradualmente ganhando 
capacidades crescentes de atuação e de escolhas independentes. Vale lembrar a análise de Habermas (1990) a respeito das quatro jornadas de "juridificação" em que se torna evidente a progressiva conquista de espaço de atuação política ao longo do processo que vai da constituição do Estado Burguês até o Estado Social e Democrático de Direito: enquanto no Estado Burguês a instauração de alguns poucos direitos se deu, fundamentalmente, em conseqüência da institucionalização dos subsistemas economia e administração, já na jornada seguinte, própria ao Estado Burguês de Direito, direitos de proteção à vida, à liberdade e à propriedade foram institucionalmente reconhecidos; no Estado Democrático de Direto, os cidadãos passaram a ser portadores de direitos de participação política e, finalmente, na jornada posterior, i.e., a do Estado de bem-estar social, são institucionalizadas proteções que absorvem os efeitos sociais externos do processo de produção material.

No entendimento de Offe (1987), o resultado desse conjunto de mudanças é uma expansão jamais vista do número de opções com as quais os indivíduos passam a contar nas várias esferas da vida social: na esfera da produção material, na esfera de reprodução cultural e na esfera política. $\mathrm{Na}$ esfera da produção material, o princípio de mercado concretiza, a todos os atores sociais que dela fazem parte, a existência de opções diversas frente às quais pode-se decidir onde comprar ou vender produtos, e o que e como produzir. Sem dúvida, isso se faz acompanhar de processos de reificação, de monetarização da vida social. $\mathrm{Na}$ esfera das normas culturais e valores, os monopólios tradicionais de interpretação, reivindicação do absoluto e doutrinas tornam-se obsoletos abrindo novas e extensas opções no tocante às normas de orientação, ocupação, lazer, arte, família, sexualidade, religião, educação, etc. Os riscos de desintegração social tornam-se, pois, freqüentes na medida em que padrões de comportamento perdem sua validez imediata. E, finalmente, na esfera política, Offe afirma que o sistema político liberal-democrático apresenta 
um alto grau de opções de escolha aos cidadãos, sujeitas as mais rápidas variações a quem quer que tome uma posição, qualquer que seja a forma, quaisquer que sejam as questões e os interesses, ao mesmo tempo em que traz à tona situações de burocratização da vida social.

Diante disso, alternativas normativas precisaram ser elaboradas tendo em vista a necessidade de fundamentar a nova ordem social que emergiu com a modernidade. Em termos típico-ideais, pode-se afirmar que dois tipos puros de projeto normativo surgiram em resposta ao processo de individuação resultante da esgarçadura dos laços sociais fundamentados tradicionalmente: o projeto normativo liberal e o projeto normativo comunitário. Esses processos percebem os resultados da modernidade de maneiras opostas, excluindo-se um ao outro: o modelo liberal vislumbra os aspectos positivos da modernidade, acentuando a importância da desvinculação dos destinos individuais frente às concepções de mundo tradicionais; leva às últimas conseqüências o processo de individuação. $O$ modelo comunitário coloca-se de forma cautelosa diante do processo de individuação, salientando a natureza social do ser humano; apresenta como inevitável o restabelecimento de uma normatividade referenciada na coletividade de interesses e aspirações.

O que pretendemos fazer a seguir é apresentar cada um desses projetos típico-ideais de normatividade angariando elementos para, mais a frente, refletirmos sobre um projeto normativo que, ciente das características segmentadoras da modernidade, tire proveito do potencial emancipatório que ela traz em seu seio. Novamente, é preciso dizer que trabalharemos aqui de forma ideal, exagerando aspectos que na realidade mostraram-se menos precisos já que, nas suas formas concretas, resultaram do confronto de forças sociais em muitos momentos divergentes. Nossa intenção não é realizar uma análise histórica mas sim pensar estruturas normativas gerais a partir das quais se tentou responder ao processo de racionalização e individuação próprios à modernidade. 


\title{
O MODELO NORMATIVO LIBERAL E SUA CONCEPÇÃO DE DEMOCRACIA
}

O modelo normativo liberal é o resultado direto do confronto do ideário moderno com as concepções de mundo tradicionais. $O$ primado da Razão, resultante da revolução cultural impulsionada pelo Iluminismo, não media esforços "contra o poder do costume, da tradição e da autoridade" (CASSIRER, 1994, p. 315). Aqui, procura-se afastar a normatividade da idéia de direitos tradicionalmente adquiridos salientando a existência de "direitos que temos de nascença" (CASSIRER, 1994, p. 316). De acordo com Cassirer, a fundação do direito natural moderno travou combate tanto contra a doutrina teocrática, que via no direito a expressão de uma vontade divina absolutamente impenetrável e inacessível à razão humana, como também contra o absolutismo estatal.

\begin{abstract}
"Em contraste com essas duas correntes, o direito natural sustenta como tese suprema a existência de um direito que sobreleva todo poder humano ou divino e que é dele independente. $O$ conteúdo da idéia do direito como tal não teve sua fonte no domínio do poder e da vontade mas no da razão pura. Nenhum ato de autoridade pode mudar ou retirar seja o que for ao que essa razão concebe como 'existente', ao que é dado em sua pura essência” (CASSIRER, 1994, p. 322).
\end{abstract}

Quando se fala na "natureza da lei", o modelo liberal não quer com isso chamar a atenção para a sua existência física, sua realidade material, mas sim para o seu "fundamento puramente imanente" (CASSIRER, 1994, p. 325). John Locke é, sem dúvida nenhuma, a principal referência desta concepção de normatividade que salienta a imanência racional dos direitos de liberdade, igualdade e propriedade. Locke (1973) defendia a idéia de que todos os homens se acham, naturalmente, num estado de perfeita liberdade "para ordenar-lhes as ações e regular- 
lhes as posses e as pessoas conforme acharem conveniente, dentro dos limites da lei da natureza, sem pedir permissão ou depender da vontade de qualquer outro homem" (p. 41). Considerava natural a todo homem o direito à igualdade de tratamento já que "nada havendo de mais evidente que criaturas da mesma espécie e da mesma ordem, nascidas promiscuamente a todas as mesmas vantagens da natureza e ao uso das mesmas faculdades, terão também de ser iguais umas às outras sem subordinação ou sujeição" (LOCKE, 1973, p.41). Finalmente, a propriedade era considerada um direito inalienável do homem; o autor esforçou-se para mostrar "como os homens podem chegar a ter propriedade em várias partes daquilo que Deus deu à Humanidade em comum, e tal sem qualquer pacto expresso entre todos os membros da comunidade" (p. 51).

Diante desses direitos naturais e inalienáveis, o Estado só faz sentido e só se sustenta na medida em que proporciona as melhores condições para que tais direitos tenham livre curso. Frente a eles, "a função própria e o objetivo essencial do Estado consistem em dar-lhes um estatuto na ordem política, conceder-lhes sua proteção e sua caução" (CASSIRER, 1994, p. 334).

Pode-se dizer, ainda que típico-idealmente, que o processo político correspondente ao modelo normativo liberal é a democracia eletivorepresentativa. Stuart Mill, um dos mais importantes liberais a refletir a essse respeito, acreditava que nas sociedades mais complexas e numerosas a participação pessoal de todos mostra-se inviável, a não ser numa porção muito reduzida dos negócios públicos; daí que, para o autor, em sociedades como as nossas, "o tipo ideal de um governo perfeito só pode ser o representativo" (MILL, 1980, p. 38). Conforme o autor, "governo representativo significa que o povo inteiro, ou pelo menos grande parte dele, exercite, por intermédio de deputados periodicamente eleitos por ele, o poder do controle supremo, que deve existir em algum lugar em todas as constituições" (p. 47). 
Nesse sentido, o voto é o meio através do qual os cidadãos têm a oportunidade de defender seus interesses privados, escolhendo parlamentares e governantes que irão representá-los. É essa escolha que fará o impacto dos cidadãos sobre a administração uma vez que a sociedade é percebida como um mercado estruturado de uma rede de interações entre pessoas privadas dentro de limites determinados por estatutos legais (HABERMAS, 1994).

\section{O MODELO NORMATIVO COMUNITÁRIO E SUA DIMENSÃO POLÍTICA}

O tipo ideal do modelo normativo comunitário caracteriza-se pelo ceticismo diante da aclamada positividade do processo de individuação. Suas respostas aos novos processos sociais atomizantes próprios da modernidade têm um caráter, de certa forma, regressivo. Os comunitaristas salientam que os homens inscrevem-se no interior de contextos históricos e sociais cuja dinâmica se impõe sobre os indivíduos. É a referência às coletividades, às comunidades das quais fazem parte, o lugar de onde os indivíduos moldam suas identidades, sua língua, sua concepção de mundo, suas categorias morais, etc. Neste sentido, argumentam que "os ideais liberais de autonomia moral e de desenvolvimento individual são fundados sobre um conceito de tipo atomista e abstrato, senão contraditório, do sujeito portador de direitos" (COHEN \& ARATO, 1993: 49). Segundo os comunitaristas, aquilo que o modelo liberal qualifica como sendo normas universais enraizadas no caráter universal da humanidade nada mais são que normas particulares, originadas em comunidades específicas.

Dessa forma, não se considera como verdadeira a idéia da existência de direitos imanentes a indivíduos abstratos, mas sim os direitos próprios aos membros de um conjunto comunitário: "o verdadeiro fundamento da teoria moral é (...) a comunidade e seu bem, e não o indivíduo 
e seus direitos" (COHEN \& ARATO. 1993, p. 50). Há um compromisso com a comunidade que estabelece virtudes comunitárias de lealdade $\mathrm{e}$ virtude cívica a serem realizadas pelos indivíduos em suas condutas.

O processo político próprio a este tipo ideal de modelo normativo é a democracia participativa. Prima-se aqui pela autodeterminação, pela participação direta, pela igualdade política, pelos debates para a elaboração de escolhas políticas, e pela ação de uma opinião pública autônoma sobre as decisões. A democracia participativa exige que os indivíduos aprendam a tolerar as diferentes opiniões mas também a superar egoísmos (COHEN \& ARATO, 1993).

Habermas (1994) entende que nesse modelo está presente a idéia de que a autoridade governamental emerge dos cidadãos, do poder produzido comunicativamente na práxis da autolegislação dos cidadãos. No procedimento político, induz-se a uma prática comunitária da cidadania pública, para todos os níveis das instituições sociais, devendo penetrar o caráter, os hábitos e os sentimentos morais de cada cidadão (COHEN \& ARATO, 1993). Nesse sentido, a política é dotada de uma função que transcende a mera mediação de interesses privados: ela é mais constitutiva para os processos sociais na medida em que os membros da sociedade tomam consciência de sua interdependência (HABERMAS, 1994). Segundo o autor, a vantagem desse modelo em relação ao liberal é que ele "preserva o significado original de democracia em termos de institucionalização do uso público da razão exercida conjuntamente por cidadãos autônomos" (p. 3).

Feita essa breve discussão em torno dos dois tipos ideais modernos de modelo normativo, nos deteremos ao debate dos principais aspectos que dão sentido à elaboração do modelo normativo "procedimental". Nos aproveitaremos, aqui, fundamentalmente, das reflexões de Jürgen Habermas, Jean Cohen, Andrew Arato e Claus Offe para apresentar essa nova alternativa de normatividade. 


\section{O MODELO NORMATIVO 'PROCEDIMENTAL' COMO PROJETO POLÍTICO DA MODERNIDADE}

O modelo normativo "procedimental" parte de dois pressupostos que marcam o processo de modernização das sociedades ocidentais: em primeiro lugar, a complexificação e diferenciação dos subsistemas economia e administração são o resultado do processo evolutivo por que passaram nossas sociedades. Somente a complexificação e diferenciação desses dois subsistemas pôde garantir a reprodução material da vida social em complexas sociedades como aquelas em que vivemos. Os meios de controle dinheiro e poder, que mediam as interações nos âmbitos sistêmicos não podem, por isso, ser substituídos por outros meios próprios a comunidades sistemicamente mais simples ${ }^{1}$.

Não se quer dizer com isso que os subsistemas economia e administração devam permanecer inacessíveis a uma regulamentação externa a seus funcionamentos. Offe (1987), inclusive, defende que em decorrência da expansão de opções por que passam as esferas de produção material e de política pública, surgem problemas de coordenação e de compatibilidade. Daí a necessidade de mecanismos de regulação que dirijam a seleção de opções de maneira a harmonizá-las mutuamente, impedindo o livre curso de estragos que a excessiva expansão de suas dinâmicas pode acarretar. $\mathrm{O}$ que está em questão não é a supressão da burocracia, da racionalidade econômica e da divisão social. Caso isso fosse feito, haveria um desabamento fatal da produtividade, perda de toda ori-

'A respeito do meio poder, Habermas (1990b) defende que, nas sociedades modernas, "operando no âmbito das leis, a administração obedece a critérios próprios de racionalidade; da perspectiva da aplicação do poder administrativo o que conta não é a razão prática do uso das normas, mas a eficácia na implementação de um programa dado. Assim, o sistema político lida com o direito de uma maneira precipuamente instrumental..."(p. 108-9). 
entação social clara e supressão do pluralismo (COHEN \& ARATO, 1993). Deve haver uma regulação externa, proveniente dos âmbitos de ação comunicativamente mediados, mas com uma postura auto-limitada: não se trata de tomar para a sociedade civil a tarefa de gerir a reprodução material da sociedade mas de estabelecer parâmetros e objetivos para seu funcionamento que estejam de acordo com necessidades apontadas como essenciais.

O segundo pressuposto do qual se parte é que a razão comunicativa é o meio pelo qual consensos podem ser atingidos num momento em que as concepções de mundo totalizantes perderam sua eficiência na tarefa de dotar os indivíduos de interpretações em situações do cotidiano e na tarefa de estabelecer-lhes objetivos comuns. Agora, as possibilidades de interação passam a depender das condições de um entendimento racionalmente alcançado. A partir da capacidade reflexiva que a modernidade dota os indivíduos, os pontos de vista subjetivos a cada participante da interação são superados por consensos racionalmente alcançados.

Portanto, o modelo "procedimental" parte do pressuposto de que é possível elaborar normas que regulem a interação dos indivíduos a partir da ação comunicativa; tal procedimento dá flexibilidade às buscas de consenso que vão se pautar pelas particularidades das situações que exijam um determinado acordo. Mas, vale dizer que, aqui, "uma norma só pode reivindicar sua validade a partir do momento em que ela é aceita sem constrangimento por todos os participantes à argumentação (...) e no mesmo nível. (...) toda discussão prática deve ter lugar nas condições de uma participação livre e com chances iguais de todos os sujeitos envolvidos" (HONNETH, 1991, p. 46).

Apontados esses dois pressupostos fundamentais do modelo "procedimental", vamos aos elementos que o constituem.

O modelo normativo "procedimental", que tem em Jürgen Habermas sua principal referência teórica, não se afirma em contraposição 
absoluta ao modelo normativo liberal e ao modelo normativo comunitário. $\mathrm{Na}$ verdade, aproveitando-se de vários elementos que estão no cerne de cada um desses modelos, Habermas procura redirecioná-los e a eles acrescentar aspectos que melhor se adequem à dinâmica da modernidade, sempre tendo como horizonte futuro um projeto de emancipação.

Salientando o processo de individuação, o modelo liberal procurava fundamentos ontológicos individualistas na determinação de direitos. Em reação a isto, o modelo comunitário acentuou o caráter histórico e social da normatividade, defendendo a supremacia da vontade coletiva sobre os interesses particulares. O modelo "procedimental" procura assegurar as conquistas do processo de individuação que torna os indivíduos autônomos na consecução de suas preferências e aspirações mas percebe o princípio de universalidade como sendo fundamental para uma normatividade que garanta a integração social:

“Assumindo o fato de que as identidades individuais e coleti-
vassão adquiridas pelos processos complexos de socialização,
que implicam, a sua vez interiorizar as normas e as tradições
sociais e desenvolver as capacidades de reflexão e crítica 'vis-
à-vis' normas, princípios e tradições, a concepção que consti-
tui o núcleo desta teoria é uma concepção intersubjetiva e in-
terativa de individualidade e de autonomia”(COHEN \&
ARATO, 1993, p. 64).

O que se propõe aqui é colocar sobre o mesmo plano os componentes individuais e privados da esfera normativa e seus componentes públicos e associativos de tal forma que a idéia de autonomia moral não adquira a concepção de um individualismo possessivo e de tal forma que a idéia de universalidade não ganhe a concepção de preeminência do coletivo sobre o individual. 
"Numa palavra, os direitos nã̃o asseguram somente a liberdade negativa, a autonomia dos indivíduos privados e autonomizados, eles garantem igualmente interação comunicativa...dos indivíduos entre eles nas esferas públicas e privadas da sociedade civil, como [também] uma nova relação dos indivíduos com as esferas públicas e políticas da sociedade e do Estado" (COHEN \& ARATO, 1993 , p. 65).

Busca-se, pois, a igualdade sem com isso impor a similaridade.

A participação em igualdade de chances nas discussões práticas exige, de um lado, a possibilidade de acesso igualitário às informações sociais necessárias à afirmação argumentada de convicções morais e, de outro, o grau de reconhecimento social necessário à posição e à defesa das visões morais. Por isso, a concepção de justiça social aqui não se refere às condições de uma repartição igualitária ou contratual dos meios de existência, mas sim às condições institucionais e culturais que permitam aos indivíduos ter atitudes e qualidades para o exercício de liberdades (HONNETH, 1991).

Fica claro, agora, o termo democracia "procedimental": a preocupação de Habermas está em institucionalizar os procedimentos e condições ideais de comunicação. Para Habermas (1994), é importante que se tenha em mente que um tipo legítimo de "barganha" política depende de uma préregulamentação de termos justos para a busca de resultados, termos estes que sejam aceitáveis para todas as partes sobre a base de suas diferentes preferências. Assim, o processo de formação de vontade política não retira sua força legitimadora de uma prévia convergência de um conjunto de convicções éticas, e nem de direitos imanentes aos indivíduos mas, sim, de pressupostos comunicativos que permitam que os melhores argumentos prevaleçam, e de procedimentos que assegurem processos justos de barganha (HABERMAS, 1994).

As discussões a respeito do processo político neste modelo normativo sugerem a criação de novas formas de mediação entre os indiví- 
duos, entre si, e entre a sociedade civil e a economia e a administração. No primeiro caso, trata-se de garantir direitos de liberdade de pensamento, imprensa, fala, enfim, de comunicação com procedimentos que assumam o potencial reflexivo que o mundo da vida racionalizado dota os indivíduos. Revendo valores e comportamentos tradicionais, os indivíduos, isoladamente ou no interior de associações de caráter voluntário, podem pautar suas relações por uma normatividade elaborada a partir de uma motivação racional de busca de consenso.

No segundo caso, sugere-se a criação de novas relações, autolimitadas, entre as esferas institucionais do mundo da vida e o Estado e a economia. No caso dos processos políticos, não se trata, como lembram Cohen \& Arato (1993), de estabelecer um tipo de participação que substitua os organismos institucionais da democracia representativa. Trata-se, sim, de enriquecer a vida pública com novos valores e questões, contribuindo para a reprodução daquele consenso que o modelo eletivo pressupõe e não atinge. Tal modelo deve "coabitar com o sistema de partidos concorrenciais, e não ter por objetivo desbancá-los. Nossa concepção de sociedade civil conserva assim o núcleo normativo da teoria democrática afirmando-se compatível com os pressupostos da modernidade" (COHEN \& ARATO, 1993, p. 62).

No debate em torno do modelo "procedimental" encontra-se explícita a idéia de que vivemos um momento de efervescência da sociedade civil que dá sentido à expectativa de que o "projeto emancipatório da modernidade" vem se concretizando na dinâmica da vida social de forma gradativa e efetiva. Os novos movimentos sociais, dinamizados por preocupações de uma nova ordem, parecem ser os atores sociais que estão no cerne dessas transformações. É sobre essa efervescência social que falaremos a seguir. Nosso referencial teórico a respeito do conceito de sociedade civil é a reelaboração que Jean Cohen e Andrew Arato fazem do 
instrumental analítico habermasiano. Cohen (1985) defende a idéia de que Habermas, na Teoria da Af̧ão Comunicativa, realizou uma análise incompleta deste conceito. Os autores procuraram melhor especificar o que se entende por sociedade civil a partir da idéia de mundo da vida. Entendendo o mundo da vida como um reservatório de tradições e conteúdos comuns no qual se nutrem os membros de um dado grupo social em suas interações cotidianas, Cohen e Arato se centram em sua dimensão institucional, que envolve aparatos cuja tarefa é preservar tradições, solidariedades e identidades, para definir o conceito de sociedade civil (ARATO, 1995; AVRITZER, 1993; COHEN, 1985; COHEN \& ARATO, 1992 e 1993; COSTA, 1994).

\section{A Sociedade Civil Falante: UMA NOVA SOCIABILIDADE EM QUESTÃO}

O momento histórico em que a revitalização do debate em torno do conceito de sociedade civil se deu nos é extremamente próximo. Pode-se dizer que é em meados da década de 70 que o papel político da sociedade civil passou a ser revigorado e apontado como o locus de um novo processo emancipatório. A efervescência das atuações de indivíduos associados voluntariamente deu margem a perspectivas de novas formas de sociabilidade. As dinâmicas que a vida social, política, econômica e cultural que o Leste europeu, a Europa Ocidental e os Estados Unidos, e a América Latina ganharam nos anos 70 são apontadas como a origem de processos que vieram se desencadear na redefinição de questões políticas e culturais. Afirma-se que esse processo teve início exatamente na Polônia quando da emergência de movimentos populares - como o Solidariedade - que levantavam a bandeira política da liberdade de expressão, 
da liberdade de associação e reunião, de participação política, enfim, de termos correntes nas democracias políticas do Ocidente (AVRITZER, 1993; ARATO, 1995; COHEN \& ARATO, 1993; COSTA, 1994).

Nos Estados Unidos e Europa ocidental esse processo é associado à emergência dos novos movimentos sociais em reação a um conjunto de fatores que atestava a incapacidade do Estado de bem-estar social de encontrar respostas a problemas de ordem social e cultural. Reage-se contra as perversidades do excessivo intervencionismo do Estado keynesiano em esferas da vida que passaram a ser regulamentadas e controladas por meios administrativos, prejudicando os processos de reprodução cultural, integração social e socialização e de formação da opinião pública e da vontade política.

$\mathrm{Na}$ América Latina, o revigoramento do debate em torno do conceito de sociedade civil se deu em meio a um processo em que, paralelamente à abertura política, surgiram novas formas de se fazer política e de se exigir direitos. Os movimentos sociais na América Latina representaram a entrada em cena de setores sociais tradicionalmente excluídos da vida política que, desvinculados da dinâmica partidária e dos sindicatos, lutavam pelo atendimento de carências básicas e pela ampliação do acesso ao espaço público (Cardoso, 1984; DURHAM, 1984).

Assim, esses três contextos marcam o início de um debate que passa a salientar a organização autônoma de setores sociais, desvinculados dos espaços de circulação dos meios de controle administrativos e econômicos, que deram início à reconstrução de laços sociais, referências sociais e espaços de socialização que vinham se perdendo ao longo dos anos que os antecederam. Assinala-se, pois, a emergência de um grande número de associações espontâneas, em que os indivíduos relacionam-se livres de quaisquer coerções, onde prevalecem contatos horizontais que refletem o adensamento de práticas intersubjetivas de deliberação e execução de questões em torno das quais esses indivíduos se coadunam 
(HABERMAS, 1990b). Afirma-se que tal emergência liga-se ao surgimento de problemas que se localizam nos "pontos de sutura" entre as esferas sistêmicas e o mundo da vida fato que as faz adotar uma postura de 'defesa' dos âmbitos comunicativamente mediados frente aos subsistemas economia e administração; mas, afirma-se também que tais associações postam-se "ofensivamente" na medida em que "tentam colocar questões de relevância para o conjunto da sociedade, (...) [buscando] interpretar valores de novas maneiras e mobilizar-se pelas boas causas, denunciando as más, [além de] exercerem pressão sobre o parlamento, a justiça e os governos em favor de determinadas políticas" (COSTA, 1994, p. 48): buscam. pois, fortalecer uma terceira arena de poder, que possa fazer frente ao Estado e ao mercado, reforçando seu papel central na integração social.

Todas essas características dão certa unidade aos fenômenos sociais que tiveram lugar no Leste europeu, na Europa Ocidental e Estados Unidos, e na América Latina podendo ser entendidos, guardadas as suas especificidades, como dinâmicas sociais que resultaram de transformações recentes das sociedades industriais. Considerando as particularidades dos aspectos que caracterizam cada um daqueles contextos, podemos colocar num mesmo plano as conseqüências negativas que os Estados autoritários do Leste da Europa e da América Latina e o Estado Keynesiano no Ocidente europeu e nos Estados Unidos provocaram na reprodução simbólica dessas sociedades. Esses processos concretizaram aquilo que Habermas qualifica como "colonização sistêmica do mundo da vida". A reação dos indivíduos associados voluntariamente, à margem das esferas políticas "oficiais", buscando um novo desenho político que almeja socializar a política e o poder sem querer tomar para si as tarefas próprias à administração e ao mercado são também indícios de que esses fenômenos fazem parte de um mesmo processo. São aspectos que dão sentido às expectativas de que o ressurgimento da sociedade civil, dina- 
mizada por novos princípios, possa levar adiante o projeto inacabado da modernidade.

Mas, para além dessa inegável unidade, estamos cientes das diversidades daqueles que dão dinâmica à sociedade civil. A bibliografia que se detém a esse respeito assinala vários aspectos que marcam descontinuidades e que sugerem as dificuldades de se pensar um projeto político único. Arato (1995) lembra que as associações e grupos sociais, de fato, não se apresentam num plano único: o tamanho, a lógica, a extensão temporal e espacial, o papel político, o nível de organização, o número de questões discutidas, o papel dos interesses, o processo de formação de identidades são muito diferentes em cada um deles. $O$ ressurgimento da sociedade civil é, sem dúvida nenhuma, marcado por essas descontinuidades, como não poderia deixar de ser, tendo em vista a 'polifônica' modernidade em que se encontram inseridos, e as particularidades dos contextos em que emergem. A riqueza dessas diferenças não poderia ser desconsiderada sem que se incorresse num equívoco sociológico.

Conforme afirmamos, a bibliografia que lida com a temática da sociedade civil é bastante reveladora desses aspectos. Tendo isso em mente, procuraremos, a seguir, pensar os principais atores da renovada sociedade civil - os novos movimentos sociais - em quatro aspectos: os atores sociais que deles fazem parte, as questões por eles levantadas, seus valores, e seus modos de ação/organi-zação. Com isso, apresentaremos alguns dos elementos que lhes dão unidade.

\section{OS Novos MOVIMENTOS SOCIAIS: AS LUTAS EM TORNO DA GRAMÁTICA DAS FORMAS DE VIDA}

Os novos movimentos sociais são os atores sociais e políticos que se nos apresentam levantando questões e sugerindo novos modelos de sociabilidade em resposta à dinâmica que as sociedades ganharam no seu 
período de industrialização avançada. A questão que de início nos surge é, pois, até que ponto os novos movimentos sociais representam uma continuidade em relação aos movimentos emancipatórios anteriores $\mathrm{e}$ qual o momento em que o rompimento desse continuum define os aspectos característicos que lhes dão especificidade? O que os movimentos da última terceira parte do século $\mathrm{XX}$ têm em comum com os movimentos burgueses emancipatórios dos séculos XVIII e XIX e em relação aos movimentos dos trabalhadores dos séculos XIX e XX e em que momento eles se diferenciam?

Claus Offe (1987) defende que os movimentos políticos e sociais da burguesia dirigiam-se contra os privilégios de tomada de decisão e contra as arbitrariedades das elites políticas pré-burguesas. Já, os movimentos dos trabalhadores dirigiam suas preocupações contra a pobreza $\mathrm{e}$ a desigualdade social que vinham se expandindo com o processo de industrialização. $O$ autor salienta que o Estado democrático constitucional é a própria realização evolucionária que emergiu da conjunção parcial do movimento social da burguesia com o florescente movimento dos trabalhadores.

O Estado de bem-estar social, constituído no pós-II guerra das sociedades da Europa ocidental, por sua vez, foi forjado - não só mas também - a partir das reivindicações do movimento não comunista dos trabalhadores. Do pós-II guerra até os anos 70 , as questões centrais aos movimentos eram, fundamentalmente, aquelas relativas ao crescimento econômico, à distribuição de riqueza e à segurança, deixando de lado conflitos sobre a ordem institucional e legal das sociedades nacionais (OFFE, 1985). Acreditava-se que os mercados livres eram, funcionalmente falando, os mais eficientes na continuação do crescimento econômico; não se concebia qualquer outro arranjo melhor na execução dessa tarefa. O Estado de bem-estar social, atuando de forma a aparar as conseqüências maléficas do mercado, era legitimado na tarefa de distribuir a produção de riquezas, assimilando as reivindicações do movi- 
mento operário além de proporcionar garantias contra 'comportamentos desviantes' que pusessem em cheque a ordem legal, econômica, política e familiar (OFFE, 1985). O arranjo político estabelecido e concordado era a forma de democracia política, mediada por partidos representativos em competição.

Pode-se dizer, então, que os atores desses movimentos eram grupos definidos sócio-economicamente - as classes sociais - envolvidos, fundamentalmente, no conflito distributivo. As questões nas quais centravam suas preocupações eram aquelas relativas ao crescimento econômico, distribuição e seguridade social; e seus modos de ação eram, no plano interno, a organização formal de associações representativas de larga escala e, no plano externo, a competição político-partidária e a intermediação de interesses pluralistas e corporativistas (OFFE, 1985).

A continuidade dos novos movimentos em relação aos que os precederam, para o autor, está no fato de que, em primeiro lugar, sem as realizações acumuladas dos movimentos democrático-burgueses e socialistas-proletários não haveria nem a ocasião nem a possibilidade dos novos movimentos sociais emergirem. Em segundo lugar, os valores centrais dos novos movimentos sociais - a liberdade individual, a autonomia e os princípios universalistas e humanistas -, são valores, em sua origem, modernos; o que na verdade ocorre é uma mudança de ênfase e um redirecionamento novos desses valores. É isso que, para Offe (1985), caracteriza os novos movimentos sociais como não sendo nem pré-modernos e nem pós-modernos:

\footnotetext{
“eles são, na verdade, contemporâneos das sociedades em que vivem e contra cujas instituições de racionalidade econômica e política se opõem. Essa oposição não ocorre primariamente entre 'velhos' e 'novos valores' mas entre pontos de vista conflitantes (...) dentro do repertório de valores modemos" (OFFE, 1985 , p. 849).
} 
Feitas essas primeiras considerações, discorreremos, agora, sobre aqueles elementos que marcam a descontinuidade dos novos movimentos sociais a partir de quatro aspectos-chave: atores, questões centrais, valores, e modos de af̧ão/organizaçãó2.

É freqüente na bibliografia a idéia de que a posição sócioeconômica dos atores que compõem os novos movimentos sociais é, fundamentalmente, a classe média, a despeito de não fazerem a defesa de interesses de classe, no sentido clássico do termo: os atores dos novos movimentos sociais, de fato, não levam adiante os valores clássicos de uma classe sócio-econômica (BAGGULEY, 1992; COHEN, 1985).

A esse respeito, Eder (1985) entende que os novos movimentos sociais são, historicamente falando, uma segunda onda do protesto do 'homem honesto' e 'democrata radical' pequeno burguês do século XIX. Para o autor, a moralidade da nova pequena burguesia é uma continuidade daquela tradição: “o retorno à experiência direta, à natureza antropomorfa e o velho sonho da paz eterna, liberação pelo grupo e no grupo são lugares-comuns que reformulam o antigo pensamento pequeno burguês” (p. 877). Segundo Eder, este tipo de protesto coletivo está baseado em uma estrutura objetiva que é característica da pequena burguesia: no seu desenvolvimento, é a parte da burguesia que nunca foi bem sucedida em tornar-se realmente burguesa, mas nunca tornou-se proletariado em função de seu controle sobre os meios de produção e atividades estatalburocráticas. Hoje, o avanço social da classe média encontra-se ligado ao desenvolvimento da chamada sociedade de serviço que vem fazendo emergir uma nova classe média: nela, chamam a atenção os administradores dos clientes do Estado de bem-estar, os assistentes sociais, psicólogos, professores, etc., enfim, aqueles que promovem os reparos sociais, cuja tarefa é zelar pelas compensações sociais de outras pessoas, e não deles mesmos.

${ }^{2}$ Seguimos aqui a sugestão esquemática de Claus Offe (1985). 
Offe (1985) compartilha com Eder a idéia de que a base social dos novos movimentos é, em sua essência, a nova classe média. Algumas de suas principais características são: seu alto nível de informação, uma segurança econômica relativa e a ocupação de serviços pessoais. Isso lhes permite um mais fácil acesso à natureza particular dos problemas contra os quais se organizam e melhores condições de julgamento sobre aspectos sistêmicos "abstratos" e complexos. Suas demandas são "classunspecific", dispersas e até mesmo universalistas. De acordo com o autor, a "política da nova classe média, em contraste com a maioria das políticas da classe trabalhadora, (...) é tipicamente uma política de uma classe mas não em benefício de uma classe"(OFFE, 1985, p. 833).

As questões em torno das quais os novos movimentos sociais se concentram podem ser definidas, ainda que genericamente, como sendo aquelas vinculadas ao medo e à ansiedade resultantes das violações ou ameaças à integridade física e simbólica do corpo, da vida ou do modo de vida por parte de arranjos institucionais da sociedade industrial avançada, por parte da sua produção material e a inovação científico-tecnológica a ela vinculada (OFFE, 1987). Se nos séculos XVIII e XIX o eixo de preocupação dos movimentos liberal-burgueses era Liberdade $X$ Privilégio, se nos séculos XIX e XX o eixo de luta do movimento trabalhador socialdemocrata era Justiça Social e Segurança Econômica $X$ Propriedade Privada $e$ Poder Econômico, o eixo de conflito em torno do qual os novos movimentos sociais se concentram é Medo, Dor e Destruição (física ou simbólica) $X$ Integridade, Reconbecimento e Respeito (OFFE, 1990).

A referência principal aqui é, sem dúvida nenhuma, a análise realizada por Habermas; segundo o autor: "os novos conflitos se desencadeiam não em torno de problemas de distribuição, mas em torno de questões relativas à gramática das formas de vida" (HABERMAS, 990c, p. 556).

Vale lembrar que, para Habermas, somente os âmbitos de ação que cumprem funções econômicas e administrativas podem ficar regula- 
dos pelos meios de controle dinheiro e poder. No momento em que esses meios transbordam as esferas sistêmicas atuando nos âmbitos de reprodução cultural, de integração social e de socialização - âmbitos, portanto, comunicativamente estruturados -, ocorre o que o autor chama de colonização sistêmica do mundo da vida. O resultado é o aparecimento de 'patologias laterais', tais como perda de sentido, perturbações de identidade coletiva, anomia, perda de motivação, crise de orientação, alienação, psicopatologias, perda de tradições, e outras. É em torno desses problemas, resultantes dos processos de reificação, que emergem os novos movimentos sociais, lutando contra os 'déficits comunicativos' que a reprodução cultural, a integração sistêmica e a socialização sofrem. Daí não poderem ser apaziguados por compensações financeiras ou por mecanismos burocráticos. $O$ fato de se ligarem a questões de qualidade de vida, de igualdade de direitos, de autorrealização individual, de participação e de direitos humanos os diferencia substancialmente dos "antigos" movimentos.

Nesse sentido, tendo em Habermas uma referência central, Claus Offe (1990) entende que o desapontamento dos novos movimentos sociais se relaciona com as falhas evidentes e os impactos negativos do processo de modernização.

"A crítica é direta contra as dinâmicas de crescimento industrial e mudança técnico-científica que tornaram-se autonomizadas... de todos os laços sociais de responsabilidade, de um lado, e contra o funcionamento de um 'welfare warfare state' comprometido com o valor central de segurança (social e militar), de outro" (OFFE, 1987, p. 15).

As questões são uma resposta aos efeitos colaterais negativos da 'expansão sem fronteiras' da racionalidade econômica e política invadindo a infra-estrutura simbólica das informais relações sociais e da 
produção de significados. Assume-se, assim, que as instituições econômicas e políticas existentes são estruturalmente incapazes de lidar com ameaças globais, riscos e privações fomentados por elas mesmas (OFFE, 1985).

Em relação aos valores sobre os quais os novos movimentos sociais emergem, já tivemos oportunidade de mostrar como representam continuidades frente aos "antigos" movimentos, caracterizando-os como reações essencialmente modernas às sociedades em que se encontram. Vale aqui, contudo, chamar a atenção para a releitura que os novos movimentos fazem desses valores. Defendem que liberdade individual, autonomia e princípios humanistas e universalistas não podem ser atingidos através do progresso técnico-científico - como acreditavam os movimentos que os precederam -, mas através de uma recuperação da noção da importância das relações comunicativamente mediadas sobre bases não mais tradicionais. Inglehart (1990) entende que essa mudança de enfoque marca a modificação de ênfase em direção a valores pósmaterialistas, isto é, valores que priorizam a auto-expressão e a qualidade de vida em oposição àqueles que dão prioridade à segurança econômica e física (os valores materialistas). $\mathrm{O}$ autor aponta o movimento ambientalista como o exemplo primordial dessa mudança de ênfase pósmaterialista: com uma referência explícita à qualidade do ambiente físico e com uma preocupação com a qualidade do ambiente social "eles buscam relações menos hierárquicas, mais íntimas e informais entre as pessoas" (p. 45). Para nós, porém, os novos movimentos ambientais devem ser entendidos como portadores de uma crítica moderna da modernização (OFFE, 1985).

Finalmente, os novos movimentos sociais têm uma forma de organização e um modo de ą̧ão que lhes dão especificidade.

Do ponto de vista organizacional, lhes é característica, num momento inicial de constituição, a indiferenciação de status entre seus membros: há uma confiança na "desdiferenciação" no processo de to- 
mada de decisões entre aqueles que fazem parte do movimento, predominando, por isso, uma pobre e transitória demarcação entre funções de "membros" e de "líderes" (OFFE, 1985); ao invés de líderes, no sentido formal do termo, há "spokespersons" ou organizadores que executam determinados serviços. À medida em que os movimentos vão se fortalecendo e ampliando suas atividades e o número de seus membros, sente-se a necessidade de uma auto-transformação em direção a maior organização, momento em que ocorre maior formalização dos papéis dos membros de forma a tornar mais explícita a diferença entre, de um lado, membros e não-membros e, de outro, membros e líderes (OFFE, 1990).

Percebe-se grande resistência à institucionalização por parte de seus membros: resiste-se, de um lado, ao processo de institucionalização e formalização internas ao movimento. Segundo Offe (1990), há a oposição daqueles que temem que qualquer passo em direção à formalização pode envolver a perigosa burocratização, centralização, alienação e desradicalização. Nesse ponto de vista, a atividade de protesto, espontânea, local... é mais efetiva e promissora para as causas do movimento; qualquer formalização organizacional que vá além da "rede perdida" de iniciativas independentes torna-se suspeita de contraproducente. Há reais temores de que a institucionalização seja paga por perda de autonomia, perda de identidade e desenraizamento.

Este primeiro aspecto se une à resistência de formalizar uma participação na política "oficial”. Por isso é que os movimentos agem de forma mais independente do que os movimentos que os precederam. Eles têm reservas, até mesmo, àqueles partidos de protesto que afirmam representá-los na política parlamentar (RUCHT, 1990). Tal rejeição liga-se à idéia de que os meios administrativos "oficiais" encontram-se exauridos na tarefa de resolver alguns dos mais importantes problemas na moderna sociedade: 


\begin{abstract}
“em áreas de política onde as paixões, identificações, significados coletivamente compartilhados e predisposições morais dentro do 'mundo da vida' de atores sociais (e não seus interesses econômicos) são os parâmetros essenciais que precisam ser mudados para se atingir uma solução, os... modos convencionais de intervenção são virtualmente inefetivos ou mesmo contraprodutivos" (OFFE, 1990: 247-48).
\end{abstract}

Scherer-Warren (1995) assinala, ainda, que os movimentos buscam travar relações plurais através de redes de atuação formada por setores diversos. Busca-se, através de fóruns, encontrar soluções para problemas que estejam em questão. Com isso, visa-se "a ampliação do espaço da cidadania e democratização do poder local e regional" (p. 170). Através da formação dessas redes, procura-se, juntamente com setores de agências financiadoras de projetos populares, segmentos dentro do Estado, diferentes ONGs, lideranças formais e informais a "construção de um movimento social mais amplo, que possa visar transformações no âmbito local, regional, nacional e às vezes transnacional" (SCHERERWARREN, 1995, p. 176).

Sugeridas essas características próprias, fundamentalmente, aos novos movimentos sociais da Europa Ocidental e Estados Unidos que mostraram-se envolvidos principalmente com questões que se referem à "gramática das formas de vida" -, a questão que se nos apresenta é: como pensar esses aspectos caracterizados pelo debate em torno dos novos movimentos sociais em um país como o Brasil? Em que medida a revitalização da sociedade civil brasileira levanta questões que giram em torno de problemas da 'gramática das formas de vida'? Nossa intenção aqui é problematizar algumas das particularidades dos novos movimentos sociais brasileiros tendo como referência a análise até aqui realizada. 


\section{Novos MOVIMENTOS SOCIAIS BRASILEIROS: ENTRE A DISTRIBUIÇÃO DE RIQUEZAS E A GRAMÁTICA DAS FORMAS DE VIDA}

A experiência da revitalização da sociedade civil na Europa ocidental não pode ser colocada, indiscriminadamente, em 'pé de igualdade' com a experiência brasileira por motivos óbvios: os contextos sociais, políticos, econômicos e culturais têm particularidades decisivas aos novos atores sociais e políticos que têm entrado em cena nos últimos 20 30 anos na Europa e no Brasil. Apenas para constar, vale dizer que o crescimento econômico atingido pela maior parte dos países da Europa ocidental aliado à forte mobilização da população, impulsionada por uma cultura política marcadamente democrática (principalmente no pós-II Guerra), proporcionaram uma conjunção de fatores que possibilitou níveis de vida e satisfação de necessidades impensados para um país como o Brasil. Questões de saúde, educação, transporte, alimentação, habitação e outros, na plena vigência do Estado de bem-estar social, deixaram de ser problemas sociais que afligiam os atores políticos e sociais que emergiram em fins dos anos 60 , início dos anos 70 .

No Brasil, por outro lado, assistiu-se a um processo de industrialização desordenado, feito às custas da pobreza de boa parte da população que, de uma hora para outra, viu-se expulsa do campo sem quaisquer recursos políticos, econômicos e culturais para reivindicar a sua parte na economia em crescimento. $\mathrm{O}$ quadro que daí se forjou foi dos piores: centros urbanos inchados, desigualdade econômica e social separando estratos sociais por distâncias abissais, e uma cultura política que muito lentamente foi apresentando à população a importância da palavra 'cidadania'. Saúde, alimentação, habitação e outros são problemas que se misturaram a questões próprias da 'gramática das formas de vida'. O país vive, então, o surgimento de problemas típicos das sociedades industriais avançadas simultaneamente a questões ligadas à distribuição de riqueza.

Temáticas, Campinas, 6(11/12):55-90 jan./dez. 1998 
Não é de se estranhar, pois, que os movimentos ambientalistas brasileiros, ao lado da defesa de reservas florestais e da qualidade do ar dos centros urbanos, reivindiquem saneamento básico para bairros inteiros de grandes cidades; que movimentos feministas lutem pelo aumento do número de maternidades e pela melhoria no atendimento às gestantes de setores sociais desprivilegiados; que movimentos de direitos humanos exijam maior atenção a presidiários condenados não por divergências político-ideológicas mas em conseqüência de atos isolados estimulados pela condição de miséria em que se encontram. Nesse sentido:

\begin{abstract}
"Enquanto na Europa e América do Norte são entendidos como 'novos movimentos sociais' sobretudo os movimentos de mulheres, ecológicos, pacifistas e anti-nucleares, abriga-se sob o conceito, na América Latina, entre outros, ao lado de grupos de mulheres e preservacionistas, associações de trabalhadores fora das estruturas partidárias e sindicais 'tradicionais', grupos de ajuda mútua dos pobres e desempregados, comunidades eclesiais de base, associações de base étnica, movimentos regionais, como também, iniciativas nos campos de uma educação e uma arte populares" (COSTA, 1994, p. 48).
\end{abstract}

Cardoso (1984), num trabalho que marcou o debate em torno da emergência dos movimentos sociais no Brasil, mostra que os anos 70 trouxeram à cena política setores sociais populares que até então eram excluídos da dinâmica política do país. Já que tais atores não expressavam estritos interesses de classe, passaram a ser qualificados de 'classes populares'; “o seu uso é quase metafórico, pois sintetiza a idéia de grandes contingentes (massas) de baixa renda que, apesar de indefesos, guardam a capacidade de distinguir suas necessidades básicas e irromper de tempos em tempos, reclamando maior igualdade. Foi privilegiando a dimensão política que se definiu este novo ator que não luta apenas por 
melhores salários, mas generaliza suas reivindicações buscando uma sociedade mais democrática" (CARDOSO, 1984, p. 224). Verificou-se, então, que as 'classes populares' atuavam num duplo jogo, a saber, a luta pelo reconhecimento de direitos de cidadania e a viabilização de demandas, diminuindo as carências em torno das quais se organizavam.

Também Durham (1984) mostra que os movimentos sociais reivindicam o atendimento de novas necessidades, lutando pelos benefícios do desenvolvimento econômico $e$ pela ampliação do acesso ao espaço político. A autora chama a atenção também para o fato de que os movimentos sociais não se restringem àqueles com uma base nitidamente popular. Segundo Durham (1984), "o crescimento das cidades não afeta apenas as camadas mais pobres, e as modificações concomitantes nos padrões de consumo não se restringem à necessidade de novos serviços públicos, mas afetam profundamente todo o modo de vida, provocando a emergência de uma nova cultura, no sentido antropológico. $\mathrm{O}$ movimento feminista e o movimento ecológico são os exemplos mais claros dessa transformação cultural" (p. 26). Para a autora, "esse tipo de movimento talvez corresponda a transformações recentes da sociedade industrial capitalista" (p. 25).

É interessante a idéia trabalhada por Cardoso e Durham de que a partir de carências que lhes são comuns, diferentes indivíduos unem-se estabelecendo identidades coletivas. Tais carências variam muito, indo desde a ausência de elementos que são básicos à vida nas cidades até o sentimento de tratamento discriminatório: isso dá sentido à emergência de movimentos como o das mulheres, dos homossexuais, dos negros, dos moradores de uma rua, dos freqüentadores de um parque público ou de usuários de um determinado serviço (DURHAM, 1984). Aqui, pouco importa se existem diferenças de nível econômico entre os participantes já que é o compartilhar de carências, percebidas como injustas, que possibilita a formação dos movimentos (CARDOSO, 1984). E o mais interessante: "Algumas vezes, parece que os movimentos sociais saem à rua 
para perder. Conta menos a vitória que a união em si, que o sentimento de perder." (CARDOSO, 1984, p. 234).

O lado expressivo e o lado reivindicativo, nesse sentido, encontram-se sempre e necessariamente juntos entre os movimentos contemporâneos (Cardoso, 1984). É como se os membros dos movimentos quisessem reatar laços sociais, identidades e percepções de mundo a sua volta perdidos com as violentas transformações que a modernização da sociedade brasileira acarretou. Naturalmente, essas reconstruções se dão sobre bases novas, não tradicionais, como dão mostras as questões em torno das quais os movimentos emergem. A experiência de 'publicizar' carências faz ampliar a sociabilidade dos atores envolvidos nos movimentos em esferas que não se restringem às da vida privada: é um novo processo em que se verifica a constituição de pessoas na esfera pública (DURHAM, 1984). Segundo a autora, “os movimentos são plenamente sociais, não apenas por suas características internas, mas inclusive pelo fato de estarem voltados 'para fora', estabelecendo novos canais de comunicação dos indivíduos com a sociedade e o Estado. Sem isso, seriam antes seitas que movimentos" (p. 29).

Os movimentos sociais brasileiros guardam, como uma de suas características centrais, uma autonomia e independência frente às esferas políticas "oficiais". O receio de se vincularem a partidos políticos se liga às possibilidades de desvirtuamento de seus fundamentos; no momento em que são usados com objetivos político-partidários, há uma quebra do consenso interno sobre o qual criam suas identidades (CARDOSO, 1984; DURHAM, 1984).

Por fim, vale aqui constatar que apesar de parte dos movimentos sociais no Brasil se organizar formalmente através de mecanismos de representação e escolha de líderes, é o modelo comunitário de organização que se encontra em expansão: desprivilegiando a institucionalização da representação, acentua-se a participação permanente tanto no processo de tomada de decisão como na própria execução (DURHAM, 1984). 
Esses aspectos nos fazem discordar da argumentação de Costa (1994), conforme a qual, frente aos diferentes universos empíricos da América do Norte e Europa ocidental, de um lado, e do Brasil, de outro, a unidade do 'fenômeno' social dos novos movimentos só pode se manter a partir do aspecto 'autonomia/ independência em relação ao Estado', cujo resultado é a produção de uma nova dinâmica política. Somente isso, para o autor, consegue desfazer o 'impasse conceitual' decorrente da diferença dos tipos de reivindicação dos novos movimentos em cada um dos diferentes contextos.

Para nós, as semelhanças vão além desse aspecto levantado: primeiramente, se, de um lado, os novos movimentos sociais brasileiros lutam por questões ligadas à distribuição de riquezas, de outro, lutam também por aspectos que apontam para uma nova gramática das formas de vida: a existência expressiva de movimentos feministas, étnicos, homossexuais, ambientalistas/ecológicos e a ênfase dada pelos outros movimentos à igualdade dos cidadãos e à publicidade de carências são reveladoras da luta por formas de vida emancipadas, não-tradicionais.

Em segundo lugar, se de fato vivemos problemas de segurança social já superados pelos países centrais, por outro lado, experienciamos problemas típicos das sociedades industriais avançadas. Urbanização acelerada, êxodo rural, convivência de indivíduos com "backgrounds" culturais bastante diferentes sem dúvida impulsionam processos que, como falamos anteriormente, estão na base da modernidade: também no contexto brasileiro assiste-se ao enfraquecimento do poder interpretativo de concepções de mundo tradicionais, a esgarçadura do tecido social e problemas ligados à formação de identidades.

Em terceiro lugar, há que se constatar que o Estado brasileiro além de não apresentar respostas satisfatórias às demandas relativas à gramática das formas de vida, nem mesmo as necessidades básicas da população são atendidas eficientemente. A emergência, por exemplo, de associações de moradores é um dos reflexos dessa verdade. Mesmo 
quando o Estado brasileiro abre possibilidades de diálogo, como nos lembra Cardoso (1984), normalmente "todos os mecanismos que os órgãos públicos utilizam para responder às reivindicações populares levam à sua fragmentação e separação. Cada grupo se dirige a uma esfera da administração e pode se defrontar com políticas tão diversas que chegam a ser contraditórias. Em certos momentos encontram receptividade e em outros deparam com uma grande inflexibilidade" (p. 233). Assim, mais do que na Europa, o aparelho político-administrativo brasileiro mostrase ineficiente na tarefa de garantir, a partir de seus próprios meios (de controle), condições de vida ideais. Aliado a isso, vivenciamos, recentemente, uma experiência de autoritarismo político que centralizou de tal modo o processo decisório nas mãos do Estado, que a reconquista de espaços públicos nos remete às experiências dos movimentos sociais do leste da Europa.

Finalmente, busca-se redefinir as relações entre Estado, mercado e sociedade civil. É verdade que já em finais da década de 70, o aparelho do Estado mostrou-se mais acessível às reivindicações dos movimentos populares do que em momentos anteriores ${ }^{3}$. Porém, o que se passa a almejar é a institucionalização de canais que realmente concretizem o processo de socialização da política e do poder. Exemplos disso já existem: as experiências do orçamento participativo em alguns municípios, as experiências dos comitês de gestão democrática dos recursos hídricos de algumas regiões do Estado de São Paulo.

${ }^{3}$ Como nos mostra Cardoso (1984), "apesar do funcionamento tradicionalmente autoritário do Estado brasileiro, a implementação das políticas sociais (...) obriga a algum tipo de inter-relação com a população. Apesar de que nossos administradores contam com instrumentos muito eficientes para impor as razões técnicas, não podem deixar de lado as condições de demanda por seus serviços" (p. 230). 


\section{CONSIDERAÇÕES FINAIS}

Elaborações teóricas quase sempre extrapolam a concretude da realidade social que pretendem analisar. Aquilo que se tem procurado avançar no tocante ao "modelo procedimental de democracia" não poderia ser diferente: num debate com dois tipos ideais de modelos político-normativos, Jürgen Habermas delineia um terceiro, definido pelos termos que o autor entende constituírem o mundo moderno, a saber, a racionalização das concepções de mundo, a racionalização da normatividade, a busca reflexiva de identidades, e a constituição de subsistemas autônomos de economia e administração. É também daí que se depreendem os motivos e as possibilidades de uma ética do discurso, elemento básico para um modelo de democracia que, universal na garantia de condições de argumentação, preserva a "polifonia" do mundo moderno.

Os movimentos sociais aparecem como os atores centrais nas tentativas de aproximação desse modelo ideal na medida em que emergem exatamente nos pontos de sutura dos termos que estruturam o mundo moderno, apresentando questões relativas à "gramática das formas de vida", com procedimentos caracteristicamente discursivos e reflexivos.

A tentativa de se pensar esse conjunto de fenômenos no Brasil requer cautela especial diante da dificuldade que se tem de perceber se $O$ processo de modernização de nossa sociedade se completou ou não, considerando-se os mesmos termos em que os daquelas sociedades que serviram de inspiração às elaborações teóricas de Jürgen Habermas. A consideração de nossas especificidades, contudo, logo nos permite entender que os novos movimentos sociais brasileiros, ao lado da defesa de questões básicas, já resolvidas nos países mais desenvolvidos, emergem também em torno de questões próprias aos pontos de sutura entre sistema e mundo da vida, reivindicando uma participação política que acaba 
por sugerir passos significativos em direção ao idealizado "modelo procedimental de democracia". Sua dinâmica revela-nos conquistas no que diz respeito às possibilidades de emancipação assinaladas por Habermas mas que somente a luta social e o devir político poderão nos trazer elementos mais evidentes. $\mathrm{O}$ que pretendemos aqui foi, apenas e tão somente, colocar nos termos da modernidade as possibilidades de elaboração de um modelo político-normativo sobre o qual a revitalizada sociedade civil, como seus movimentos sociais, tem enorme responsabilidade.

\begin{abstract}
This article intends to stress about the "procedural model of democracy" developed by Jürgen Habermas, analysing the social actors that are in its core: the new social movements. Finnaly, we intend to consider the discussion around the organised civil society in Brazil so that possibilities of a modern political-normative project like this can be implemented, even taking into account brazilian specificities.
\end{abstract}

KEYWORDS: modernity; democratic theory; new social movements.

\title{
REFERÊNCIAS BIBLIOGRÁFICAS
}

ARATO, A. "Ascensão, declínio e reconstrução do conceito de sociedade civil - orientações para novas pesquisas". Revista Brasileira de Ciências Sociais, $\mathrm{n}^{\circ} 27$, p. 18-27, 1995.

AVRITZER, L. "Além da dicotomia Estado/Mercado - Habermas, Cohen e Arato". Novos Estudos CEBRAP, n 36, 213-222, 1993.

BAGGULEY, P. "Social change, the middle class and the emergence of 'new social movements': a critical analysis". In The Sociological Review, vol 40, nº 1, p. 26-48, 1992.

CARDOSO, R. "Movimentos sociais urbanos; balanço crítico". In: SORJ, B. \& ALMEIDA, M. H. (ORG) Sociedade e Politica no Brasil pós-64. São Paulo: Editora Brasiliense, 1984, p. 215-39. 
CASSIRER, E. "O direito, o Estado e a sociedade". In: $A$ Filosofia do Iluminismo. Campinas: Editora da Unicamp, 1994, p. 315-66.

COHN, G. "O mundo dividido". In: WEBER, M. Crítica e resignaģão: fundamentos da sociologia compreensiva. São Paulo: T. A. Queiroz, 1979, p. 3-13.

COHEN, J. "Strategy or Identity: new theoretical paradigms and contemporary social movements". Social Research, vol 52, n 4, p. 663-716, 1985.

COHEN, J. \& ARATO, A. "Un nouveau modèle de societé civile". In Les Temps Modernes, $\mathrm{n}^{\circ}$ 564, p. 40-70, 1993.

COSTA, S. "Esfera pública, redescoberta da sociedade civil e novos movimentos sociais no Brasil - uma abordagem tentativa". Novos Estudos CEBRAP,nº38, pp. 38-52, 1994.

DURHAM, E. "Movimentos sociais: a construção da cidadania". Novos Estudos CEBRAP, n 10 , pp. 24-30, 1984.

EDER, $\mathrm{K}$. 'The 'new social movements': moral crusades, political pressure groups, or social movements?”. Social Research, vol 52, n 4, p. 869-890, 1985.

GORZ, A. "Political ecology: expertocracy versus self-limitation". New Left Revien, $\mathrm{n}^{\circ}$ 202, 1993.

HABERMAS, J. "Soberania popular como procedimento - um conceito normativo de espaço público". Novos Estudos CEBRAP, n 26, p. 100113, 1990a.

Teoria de la Accion Comunicativa. 2 tomos. Buenos Aires: Taurus, 1990b. "Que significa socialismo hoje? - revolução recuperadora e necessidade de revisão de esquerda". Novos Estudos CEBRAP, n 30, p. 43-61, 1991.

"O Estado-nação europeu frente aos desafios da globalização - o passado e o futuro da soberania e da cidadania". Novos Estudos CEBRAP, $\mathrm{n}^{\circ} 43$, p. 87-101, 1995.

HONNETH, A. "Éthique du discours et concept implicit de la justice". Actuel Marx, n¹0, pp. 44-51, 1991. 
INGLEHART, R. "Values, ideology, and cognitive mobilization in new social movements". In: DALTON, R. \& KUECHLER, M. (ORG). Challenging the political order: new social and political movements in western democracies. New York: Oxford University Press, p. 43-66, 1990.

LOCKE, J. "Segundo tratado sobre o governo civil". Os Pensadores: John Locke. São Paulo: Abril Cultural, 1973.

MILL, S. Consideraf̧ões sobre o governo representativo. Brasília: Editora da UnB, 1980.

OFFE, C. "New social movements: challenging the boundaries of institutional politics". Social Research vol 52, 4, p. 817-868, 1985.

"The utopia of the zero-option modernity and modernization as normative political criteria". Praxis International, vol 7, $\mathrm{n}^{\circ}$ 1, p. 1-24, 1987.

"Reflections on the institutional self-transformation of movement politics: a tentative stage model". In: DALTON, R. \& KUECHLER, M. (ORG) 232-250, 1990.

RUCHT, D. "The strategies and action repertoires of new movements". In: DALTON, R. \& KUECHLER, M. (ORG), p. 156-175, 1990.

SCHERER-WAREN, I. “ONG na América Latina: trajetória e perfil”. In: VIOLA, E. et al. (1995).

TELLES, V. "Sociedade civil, direitos e espaços públicos". Pólis, n 14, p. 43-53, 1994. 